\title{
IN SITU IMPLANTATION OF A PROSTHETIC SYSTEMIC ATRIOVENTRICULAR VALVE IN CORRECTED TRANSPOSITION
}

Amir Elami, MD, Arthur Pollak, MD, and Gideon Merin, MD, Jerusalem, Israel

Tricuspid valve abnormalities are common in patients with corrected transposition of the great arteries (C-TGA). ${ }^{1-3}$ Anatomic abnormalities include Ebstein's malformation, straddling, dysplasia, or simply inferior displacement of the coaptation point. As a consequence, systemic atrioventricular valve insufficiency is common, occurring in up to $33 \%$ of patients with C-TGA. ${ }^{3,4}$ This valvular dysfunction is significant in that its presence or development negatively affects survival, whether treated surgically or not. ${ }^{1,4,5}$ Systemic (right) ventricular dysfunction often coexists in these patients, making it difficult to define the relative contribution of each abnormality to the progression of heart failure and shortening of survival. In contrast to normally located regurgitant tricuspid valves, where even in the presence of Ebstein's anomaly over 50\% can be repaired successfully, left-sided tricuspid valves need to be replaced in most cases. The conventional technique of valve replacement involves excision, with loss of the continuity between the valve anulus, valve tissue, chordae, and ventricular wall. Preservation of the subvalvular apparatus has been shown to maintain left ventricular performance after mitral valve replacement in both animal models and clinical studies. We applied this concept to 2 patients with C-TGA and tricuspid regurgitation requiring tricuspid valve replacement (TVR).

Clinical summaries

PATIENT 1. This patient was born in June 1990. During the first year of his life, he was hospitalized frequently because of pulmonary infections as the result of congestive heart fail-

From the Departments of Cardiothoracic Surgery and Cardiology, Hebrew University, Hadassah Medical School, Jerusalem, Israel.

Received for publication Aug 14, 1998; accepted for publication Sept 2, 1998.

Address for reprints: Amir Elami, MD, Department of Cardiothoracic Surgery, Hadassah University Hospital, PO B 12000, Jerusalem 91120, Israel.

J Thorac Cardiovasc Surg 1999;117:190-1

Copyright $\odot 1999$ by Mosby, Inc.

$0022-5223 / 99 \$ 8.00+0 \quad \mathbf{1 2 / 5 4 / 9 4 2 2 2}$ ure. Echocardiography identified C-TGA, a membranous ventricular septal defect, a patent foramen ovale, mild pulmonic stenosis, and significant tricuspid regurgitation caused by Ebstein's anomaly. Although dilated, right ventricular (systemic) function was normal. At 3.5 years of age, he underwent closure of the patent foramen ovale and ventricular septal defect, with implantation of a permanent atrioventricular (DDD) pacemaker because of intermittent complete atrioventricular block. Because he had normal right ventricular function at that time, it was decided to withhold surgical intervention for the tricuspid valve. After this procedure he remained asymptomatic for 12 months. He then started to have shortness of breath, and cardiac enlargement was evident, despite full medical treatment of congestive heart failure. Echocardiography at 5 years of age revealed moderate deterioration of systolic right ventricular function with fractional shortening (FS) of $18 \%$. Subsequently, he underwent TVR. The septal leaflet of the valve was displaced downward, and the anulus was dilated, thereby precluding leaflet coaptation. A 27-mm St Jude Medical prosthesis (St Jude Medical, Inc, St Paul, Minn) was implanted into the tricuspid valve anulus. This was achieved by interrupted stitches that ran from the atrial aspect through the anulus and around the free edge of each leaflet and then into the prosthesis sewing ring. The leaflets were therefore folded along the anulus. When examined 1 month later, he denied any symptoms. Echocardiography revealed improvement in right ventricular function (FS, 23\%) with a normally functioning prosthetic valve. In addition, he regained sinus rhythm. During his last follow-up visit, 29 months after TVR, echocardiography demonstrated a normal size-for-age systemic ventricle with mildly reduced systolic function (FS, 25\%).

PATIENT 2. This patient was initially diagnosed at the age of 6 months as having situs inversus and dextrocardia. A heart murmur was also noted. In November 1992, when she was 53 years old, she started having shortness of breath on exertion. Echocardiographic findings failed to diagnose C-TGA but were instead read as severe "mitral regurgitation," moderate "tricuspid regurgitation," and normal-size "left ventricle." 
She remained in clinically stable condition for 2.5 years with furosemide and enalapril. When she was aged 56 years, cardiac catheterization revealed a pulmonary artery pressure of 90/10 $\mathrm{mm} \mathrm{Hg}$ (mean, $60 \mathrm{~mm} \mathrm{Hg}$ ) and a pulmonary capillary wedge pressure of $24 \mathrm{~mm} \mathrm{Hg}$. Right ventricular (systemic ventricle) pressure was $92 / 12 \mathrm{~mm} \mathrm{Hg}$, and a grade $4 / 4$ systemic atrioventricular valve regurgitation was noted. Systemic vascular resistance was 20.2 Wood units, and pulmonary vascular resistance was 10.5 Wood units. Ultimately, echocardiography confirmed the diagnosis of C-TGA with a moderate decrease in systolic right ventricular function.

In November 1995, she underwent implantation of a 27 $\mathrm{mm}$ St Jude Medical prosthesis into the dilated tricuspid valve anulus, by the same technique as described for patient 1. Annuloplasty at the commissures (Kay) was used to repair the mitral valve. Intraoperative transesophageal echocardiography revealed residual grade $2 / 4$ mitral valve regurgitation (as compared with $4 / 4$ before the operation). A sequential atrioventricular pacemaker (DDD) was implanted for complete heart block. Progressive clinical improvement to New York Heart Association class I followed, with discontinuation of enalapril 6 months after the operation. For the last 8 months, she has been in sinus rhythm. Serial echocardiographic studies during the 29-month follow-up period revealed progressive improvement in right ventricular size and systolic function; the most recent study shows only a mildly dilated ventricle with a mildly reduced contraction.

Discussion. Early death rate $(10 \%)$ and late death rate (20\%) are high in patients with C-TGA and right ventricular dysfunction who require TVR for systemic atrioventricular valve insufficiency. ${ }^{6}$ The 5-year and 10-year survivals in patients with an ejection fraction of less than $44 \%$ were $49 \%$ and $19.5 \%$, respectively, whereas $100 \%$ of patients with an ejection fraction greater than $44 \%$ survived 5 and 10 years. ${ }^{6}$ This indicates that the proper timing for intervention should be before the deterioration of systemic ventricular function. For patients with atrioventricular concordance and mitral insufficiency, left ventricular dysfunction often worsens after mitral valve replacement in which the subvalvular apparatus is not preserved. Although yet unproved by controlled studies, it is likely that the same mechanism of failure occurs with the right ventricle in atrioventricular discordance. Preservation of the subvalvular apparatus in patients with C-TGA undergoing TVR should eliminate this mechanism as a factor contributing to systemic ventricular deterioration. Although the duration of follow-up for our 2 patients is rather short, both of them enjoyed significant clinical improvement and improved systemic ventricular function. Valve repair is a logical alternative to valve replacement, obviating the need to sacrifice the valve and subvalvular apparatus. However, this has been performed only infrequently, ${ }^{5,6}$ and the long-term durability of the repair, constantly exposed to systemic pressures, is unknown. ${ }^{5}$ Another alternative to TVR in such patients is the double switch operation, in which the morphologic left ventricle becomes the systemic ventricle and atrial blood is redirected accordingly. Such an approach assumes the cumulative risk of preparatory pulmonary artery banding (when necessary), the early and late risks of atrial and arterial switch operations, and the late complications of conduits. ${ }^{7}$ More experience is necessary to demonstrate an advantage of this approach over repair of the associated anomalies in CTGA with preservation of the subvalvular tricuspid valve apparatus.

\section{REFERENCES}

1. Lundstrom U, Bull C, Wyse RKH, Somerville J. The natural history and "unnatural" history of congenitally corrected transposition. Am J Cardiol 1990;65:1222-9.

2. Williams WG, Suri R, Shindo G, Freedom RM, Morch JE, Trusler GA. Repair of major intracardiac anomalies associated with atrioventricular discordance. Ann Thorac Surg 1990;31:527-31.

3. Szufladowicz M, Horvath P, Bull C, et al. Intracardiac repair of lesions associated with atrioventricular discordance. Eur J Cardiothorac Surg 1996;10:443-8.

4. Huhta JC, Danielson GK, Ritter DG, Ilstrup DM. Survival in atrioventricular discordance. Pediatr Cardiol 1985;6:57-60.

5. Horvath P, Szufladowicz M, deLeval MR, Elliott MJ, Stark J. Tricuspid valve abnormalities in patients with atrioventricular discordance: surgical implications. Ann Thorac Surg 1994;57: 941-5.

6. Van Son JAM, Danielson GK, Huhta JC, et al. Late results of systemic atrioventricular valve replacement in corrected transpostion. J Thorac Cardiovasc Surg 1995; 109:642-53.

7. Yagihara T, Kishimoto H, Isobe F, et al. Double switch operation in cardiac anomalies with atrioventricular and ventriculoarterial discordance. J Thorac Cardiovasc Surg 1994;107:351-8. 